\section{References}

1 Cornblath M, Schwartz R. Disorders of carbohydrate metabolism in infancy. Philadelphia: Saunders, 1976:155-217.

${ }^{2}$ Orzalesi M, Renzulli F, Ferrante E, et al. Trisomy 18 and neonatal hypoglycaemia. Lancet 1967;ii:1211.

${ }^{3}$ Nagel JW, Sims JS, Aplin EC II, Westmark ER. Refractory hypoglycemia associated with a malpositioned umbilical artery catheter. Pediatrics 1979;64:315-7.

${ }^{4}$ Scully RE. Case records of the Massachusetts General Hospital: weekly clinico-pathological exercises. $N$ Engl $J$ Med 1978;229:241-8

5 Mayer T, Matlak ME, Lowry SF, et al. Protean manifestations of nconatal hyperinsulinism. Ann Surg 1981;194:140-5.
${ }^{6}$ Landau H, Perlman M, Meger S, et al. Persistent neonata hypoglycemia due to hyperinsulinism: medical aspects. Pediatrics 1982;70:440-6.

${ }^{7}$ Smith DW. Recognizable patterns of human malformations. Philadelphia: Saunders, 1982:18-9.

${ }^{8}$ Pinkerton PH, Cohen MM. Persistence of hemoglobin F in D/D translocation with trisomy 12-15 $\left(\mathrm{D}_{1}\right)$. JAMA 1967;200:647-9.

Correspondence and requests for reprints to $\mathrm{Dr}$ George P Giacoia, Division of Neonatology, Department of Pediatrics, Tulsa Medical College, 6161 South Yale, Tulsa, Oklahoma 74136, USA.

\title{
Complex cardiac malformation in a case of trisomy 9
}

\section{T WILLIAMS*, I ZARDAWI $\dagger$, R QUAIFE}

Departments of Child Health*, and Pathologyt, Leicester Royal Infirmary, Leicester; and the Cytogenetics Department $\ddagger$, Nottingham City Hospital, Nottingham.

SUMMARY A case of trisomy 9 showing a complex cardiac malformation is presented with a review of other published cases. A distinct trisomy 9 syndrome can be recognised with intrauterine growth retardation, short survival, consistent facial dysmorphism, congenital heart disease, and abnormalities of the skeletal, genital, and renal systems. There is no evidence for a maternal age effect.

Trisomy 9 has been described only rarely, most commonly in mosaic form. ${ }^{1}$ This report describes a baby who died shortly after birth, in whom chromosome studies were consistent with complete trisomy 9. The cardiac abnormalities were particularly severe and of a nature not previously documented in this disorder.

\section{Case report}

The patient, a female, was the product of the first pregnancy of healthy unrelated parents, the mother and father being 31 and 30 years of age respectively at the time of birth. A subsequent pregnancy resulted in a normal infant. There is no other relevant family history.

She was delivered at 35 weeks following spontaneous onset of labour and a pregnancy marked by intermittent vaginal bleeding between the tenth and twelfth weeks. Growth parameters at birth were

Received for publication 20 August 1984 Accepted for publication 29 August 1984. weight $1.65 \mathrm{~kg}$, length $41 \mathrm{~cm}$, and head circumference $31 \mathrm{~cm}$. The baby was cyanosed at birth with irregular respirations and died at the age of $1 \frac{1}{2}$ hours.

Craniofacial abnormalities included large fontanelles with a widely split sagittal suture, bilateral microphthalmia with left corneal clouding, a bulbous nasal tip, micrognathia with a central posterior cleft of the soft palate, and very low malformed ears (fig 1). Other findings included a loud harsh systolic murmur audible all over the praecordium, single

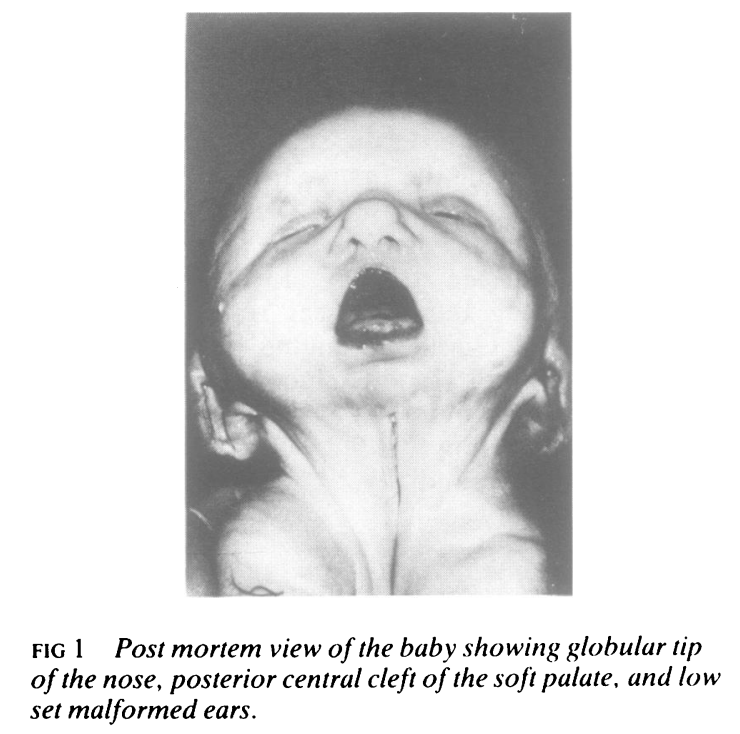

FIG 1 Post mortem view of the baby showing globular tip of the nose, posterior central cleft of the soft palate, and low set malformed ears. 
umbilical artery, camptodactyly of the fingers, bilateral dislocation of the hips, and flaccid limbs with hyperextensible elbows and knees. The spine and genitalia were normal.

Necropsy revealed a very abnormal elongated heart. The superior vena cava was small and poorly developed but the inferior vena cava was large and distended. The foramen ovale was closed and the fossa ovalus was underdeveloped. There was a large septal defect in the membranous part of the interventricular septum (fig 2). The right ventricular outflow was guarded by a tetracuspid valve, the cusps being thick, plump, and polypoid. The coronary arteries took origin from this tetracuspid valve, the left arising above the left posterior cusp and the right above the right posterior cusp. An undivided truncus arteriosus arose from the right ventricle giving off branches for the pulmonary and systemic circulations. A widely patent ductus arteriosus connected the truncus with the descending aorta. The left atrium was small and received small hypoplastic pulmonary veins. The mitral valve was also hypoplastic and the left ventricular cavity was small. The aortic valve and ascending aorta were atretic.

Other abnormalities noted at necropsy were small hypoplastic lungs with diminished lobulation, and small hypoplastic kidneys. The brain, thymus, liver, pancreas, and gastrointestinal system were normal.

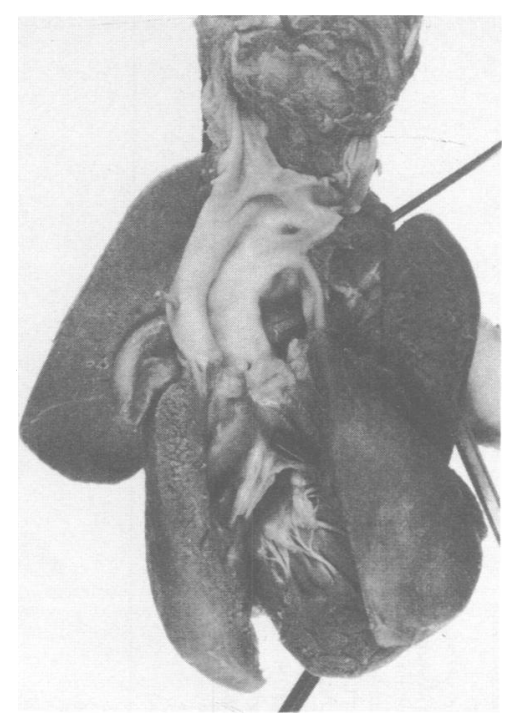

FIG 2 The heart at necropsy viewed from the right ventricle showing the ventricular septal defect (lower probe), tetracuspid right ventricular outflow valve, persistent ductus arteriosus (upper probe), and truncus arteriosus. The hypoplastic lungs are also displayed.
Chromosome analyses were performed on lymphocytes from blood collected shortly after birth. All 30 cells analysed showed an extra $C$ group chromosome identified as a number 9 with trypsin $G$ banding. No other tissue was obtained for chromosome studies.

\section{Discussion}

Although chromosomes were studied in only one tissue from this baby, the presence of an extra $\mathrm{C}$ group chromosome in all 30 cells analysed excludes mosaicism of $10 \%$ or greater with $95 \%$ confidence, $^{2}$ so that it is reasonable to conclude that she is likely to have had complete trisomy 9.

Review of the small number of well documented cases of complete trisomy 9 as summarised in the table indicates that this condition has a very distinctive phenotype. Facial anomalies present in more than $50 \%$ of cases include a prominent nose, often with a bulbous tip, low set malformed ears, microphthalmos or enophthalmos with short palpebral fissures, and micrognathia. Many of these features also occur in trisomy 13 , but the more common skeletal abnormalities of trisomy 9 (digital hypoplasia, camptodactyly, and multiple joint dislocations) help distinguish these autosomal trisomy syndromes clinically.

All cases of complete trisomy 9 have shown cardiac abnormality. Characteristic findings include a ventricular septal defect $(90 \%)$, persistent ductus arteriosus $(40 \%)$, and persistent left superior vena cava $(30 \%)$. The superior or inferior vena cavae or both were also noted to be abnormal in the baby described by Carpenter and Tomkins ${ }^{1}$ and in the subject of this report, who showed multiple severe cardiac anomalies incompatible with long term survival.

The mean birth weight of the eight surviving cases was $1 \cdot 81 \mathrm{~kg}$. Five of these babies survived for less than 24 hours. The mean maternal age at birth for these eight cases was 26.5 years, if it is assumed that each mother was aged $\mathrm{X} \cdot 5$ years where $\mathrm{X}$ equals the maternal age at birth as stated in the original publication. The mean maternal age for all births in England and Wales from 1971 to 1981 inclusive was 26.8 years. ${ }^{10}$ Thus, based on this small number of reported cases, there is no evidence for a maternal age effect. Since ascertainment of the two cases which were terminated was biased in favour of advanced maternal age, these cases have not been included in this analysis.

\footnotetext{
References

1 Carpenter BF. Tomkins DJ. The trisomy 9 syndrome. Perspect Pediatr Pathol 1982;7:109-20.
} 


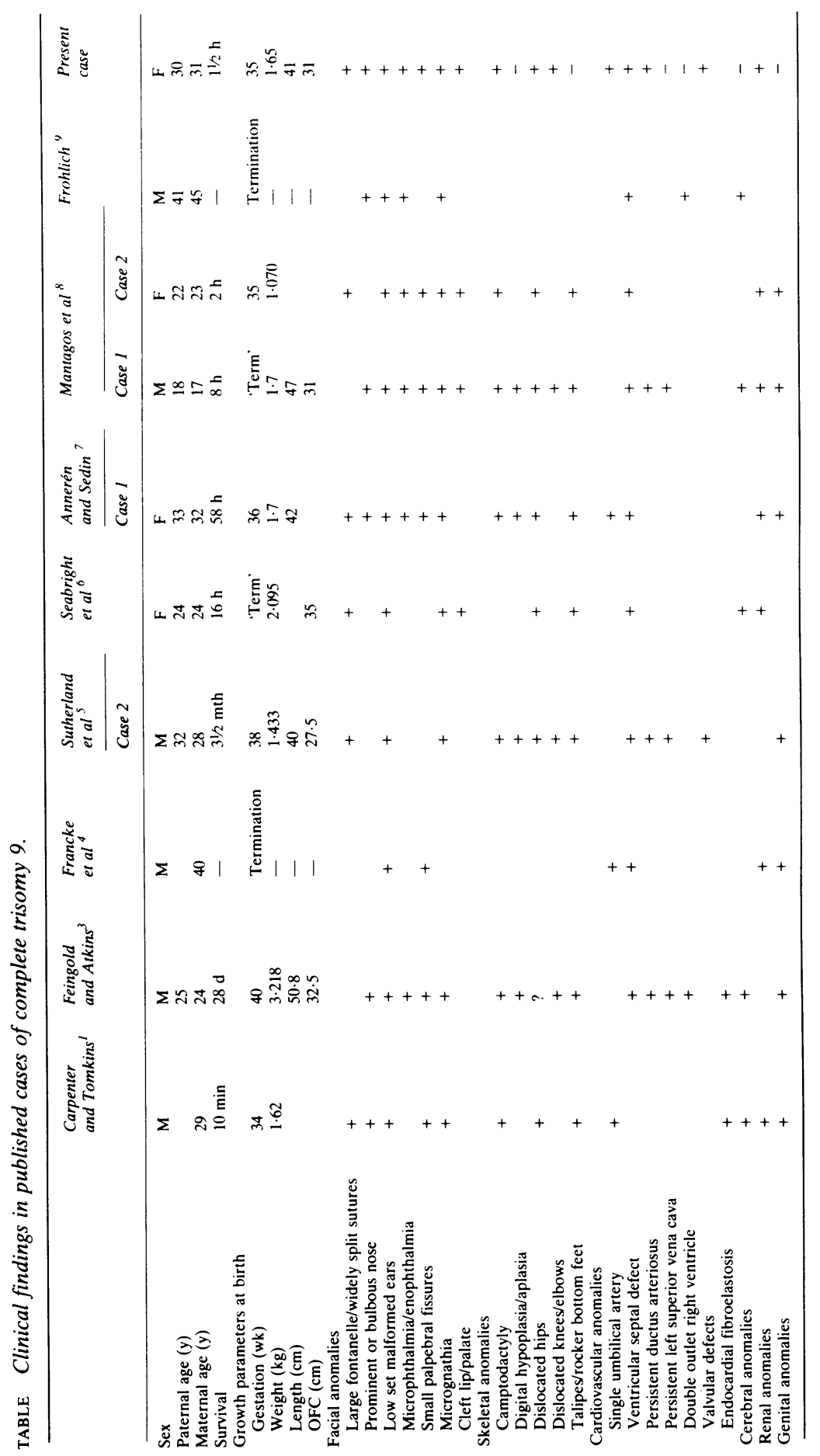


2 Hook EB. Exclusion of chromosomal mosaicism: tables of $90 \%$. $95 \%$, and $99 \%$ confidence limits and comments on use. Am J Hum Genet 1977:29:94-7.

${ }^{3}$ Feingold M, Atkins L. A case of trisomy 9. J Med Genet 1973:19:184-7.

4 Francke U, Benirschke K, Jones OW. Prenatal diagnosis of trisomy 9. Humangenetik 1975:29:243-50.

s Sutherland GR, Carter RF, Morris LL. Partial and complete trisomy 9: delineation of a trisomy 9 syndrome. Hum Genet 1976;32:133-40.

- Seabright M. Gregson N, Mould S. Trisomy 9 associated with an enlarged 9qh segment in a liveborn. Hum Genet 1976;34:3235.

7 Annerén G. Sedin G. Trisomy 9 syndrome. Acta Paediatr Scand 1981;70:125-8.
${ }^{8}$ Mantagos S. McReynolds JW. Seashore MR. Breg WR. Complete trisomy 9 in two liveborn infants. J Med Genet 1981:18:377-82.

" Frohlich GS. Delincation of trisomy 9. J Med Genet 1982:19:316-8.

${ }^{10}$ Birth Statistics. Review of the Registrar General on births and patterns of family building in England and Wales 1981. Office of Population Censuses and Surveys. London: HMSO, 1984.

Correspondence and requests for reprints to Dr I D Young, Department of Child Health, Clinical Sciences Building, Leicester Royal Infirmary, PO Box 65, Leicester LE2 7LX.

\title{
Phenotypic delineation of ring chromosome 15 and Russell-Silver syndromes
}

\author{
GOLDER N WILSON, SUE ELLYN SAUDER, MARK BUSH, AND \\ INESE Z BEITINS \\ Department of Pediatrics and Communicable Diseases, C S Mott Children's Hospital, The University of \\ Michigan, Ann Arbor, Michigan 48109, USA.
}

SUMMARY A male child with features of the Russell-Silver syndrome, including pre- and postnatal growth delay, triangular facies, bilateral fifth finger clinodactyly, and disproportionate lower extremities, was found to have a ring chromosome 15 in all peripheral leucocytes examined. Review of the reported cases of ring chromosome 15 defines a malformation syndrome with a characteristic facies related to deletion of the $15 q 26 \cdot 2 \rightarrow$ qter region. RussellSilver and ring 15 syndromes share clinical features such as growth deficiency, triangular facies, digital anomalies, and café-au-lait spots. Microcephaly, mental retardation, facial dysmorphology, limb anomalies, and cardiac defects are more striking in ring chromosome 15 patients and are indications for karyotyping when found in conjunction with the RussellSilver phenotype.

Since the original reports of Silver et $a l^{1}$ and Russell, ${ }^{2}$ a characteristic syndrome of intrauterine growth retardation, postnatal growth delay, and dysmorphic features has been delineated in over 150 reported cases. ${ }^{3-5}$ Minor anomalies associated with

Received for publication 10 July 1984. Accepted for publication 2 August 1984.
Russell-Silver dwarfism include a triangular facies, downturned corners of the mouth, fifth finger clinodactyly, skeletal asymmetry, and café-au-lait spots. We report here a patient with ring chromosome 15 who was initially diagnosed as having Russell-Silver syndrome. Review of 22 cases of ring chromosome 15 defines a clinical syndrome which is similar but distinct from that of Russell-Silver dwarfism.

\section{Case report}

The proband was the term product of an uncomplicated gestation to a 20 year old primigravida with a $6.8 \mathrm{~kg}$ weight gain. The father was 22 and the family history was unremarkable. Birth weight was $2.51 \mathrm{~kg}$ ( 3 rd centile), and length $44 \mathrm{~cm}$ ( $<3$ rd centile). Tachypnoea developed at the age of six hours owing to a small patent ductus arteriosus and treatment with digoxin was started. Following an otherwise uneventful neonatal course, there was no further sign of cardiac disease and digoxin was discontinued. Right equinovarus and left metatarsus adductus anomalies were also noted at birth and treated with serial casting. Proportionate short stature with decreased growth velocity was noted during the first two years and evaluated at $31 / 2$ and 4 years 7 months. Physical examination at 4 years 7 months revealed a height of $84 \mathrm{~cm}$ (50th centile for 18 months), a weight of $8.9 \mathrm{~kg}$ (50th centile for 8 